Provided for non-commercial research and education use. Not for reproduction, distribution or commercial use.

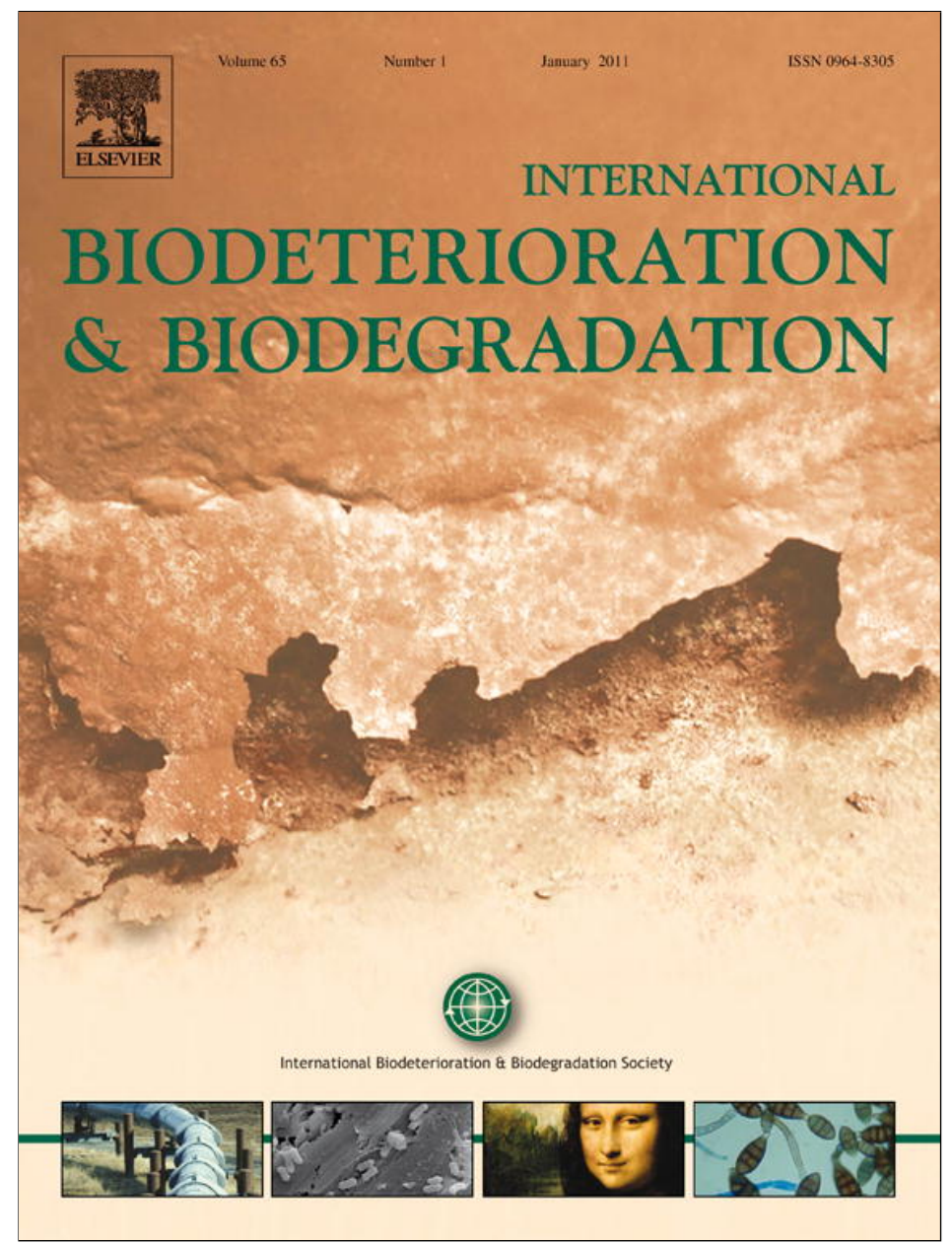

(This is a sample cover image for this issue. The actual cover is not yet available at this time.)

This article appeared in a journal published by Elsevier. The attached copy is furnished to the author for internal non-commercial research and education use, including for instruction at the authors institution and sharing with colleagues.

Other uses, including reproduction and distribution, or selling or licensing copies, or posting to personal, institutional or third party websites are prohibited.

In most cases authors are permitted to post their version of the article (e.g. in Word or Tex form) to their personal website or institutional repository. Authors requiring further information regarding Elsevier's archiving and manuscript policies are encouraged to visit:

http://www.elsevier.com/copyright 


\title{
Isolation and study of microorganisms from oil samples for application in Microbial Enhanced Oil Recovery
}

\author{
Eduardo J. Gudiña ${ }^{\mathrm{a}, *}$, Jorge F.B. Pereira ${ }^{\mathrm{b}}$, Lígia R. Rodrigues ${ }^{\mathrm{a}}$, João A.P. Coutinho ${ }^{\mathrm{b}}$, José A. Teixeira ${ }^{\mathrm{a}}$ \\ a IBB - Institute for Biotechnology and Bioengineering, Centre of Biological Engineering, University of Minho, Campus de Gualtar, 4710-057 Braga, Portugal \\ ${ }^{\mathrm{b}}$ Chemistry Department, CICECO, University of Aveiro, 3810-193 Aveiro, Portugal
}

\section{A R T I C L E I N F O}

\section{Article history:}

Received 24 August 2011

Received in revised form

14 December 2011

Accepted 3 January 2012

Available online $\mathrm{xxx}$

\section{Keywords:}

MEOR

Biosurfactant

Hydrocarbon

Degradation

Bacillus

Microbial Enhanced Oil Recovery

\begin{abstract}
A B S T R A C T
Microbial Enhanced Oil Recovery (MEOR) is potentially useful to increment oil recovery from a reservoir beyond primary and secondary recovery operations using microorganisms and their metabolites. Stimulation of bacterial growth for biosurfactant production and degradation of heavy oil fractions by indigenous microorganisms can enhance the fluidity and reduce the capillary forces that retain the oil into the reservoir. MEOR offers major advantages over conventional EOR, namely low energy consumption and independence of the price of crude oil. In this work, the isolation and identification of microorganisms capable of producing biosurfactants and promote degradation of long-chain $n$-alkanes under conditions existent in oil reservoirs were addressed. Among the isolated microorganisms, five Bacillus strains were able to produce extracellular biosurfactants at $40^{\circ} \mathrm{C}$ under anaerobic conditions in medium supplemented with hydrocarbons. Three isolates were selected as the higher biosurfactant producers. The obtained biosurfactants reduced the surface tension of water from 72 to $30 \mathrm{mN} / \mathrm{m}$, exhibited emulsifying activity and were not affected by exposure to high temperatures $\left(121^{\circ} \mathrm{C}\right)$. These characteristics make them good candidates for use at conditions usually existing in oil reservoirs. Furthermore, it was here shown for the first time that Bacillus strains were able to degrade large alkyl chains and reduce the viscosity of hydrocarbon mixtures under anaerobic conditions. The results obtained show that the isolated microorganisms are promising candidates for the development of enhanced oil recovery processes.
\end{abstract}

() 2012 Elsevier Ltd. All rights reserved.

\section{Introduction}

Oil is an essential source of energy and one of the main factors driving the economic development of the World. Its recovery comprises a primary phase, which produces oil and gas using the natural pressure drive of the reservoir; and a secondary phase, which involves stimulating the oil wells by the injection of fluids to improve the flow of oil and gas to the well-head (Lazar et al., 2007). While primary recovery produces $5-10 \%$ of the original oil in place, recovery efficiencies in the secondary stage range from $10 \%$ to $40 \%$ (Sen, 2008). Therefore, crude oil remaining in the reservoirs after conventional oil recovery operations makes up to two-thirds of the total oil reserves (Youssef et al., 2007, 2009; Suthar et al., 2008; Brown, 2010). The main factors responsible for the poor oil recovery from producing wells are the low permeability of some reservoirs, the high viscosity of the oil and the high interfacial tension between the hydrocarbon and aqueous phases, which result in high capillary

\footnotetext{
* Corresponding author. Tel.: +351 253 604400; fax: +351 253604429 .

E-mail address: egudina@deb.uminho.pt (E.J. Gudiña).
}

forces that entrap oil in small pores within the reservoir (Sen, 2008; Brown, 2010). As the price of petroleum increases and petroleum reserves shrink, exploitation of oil resources in mature reservoirs is essential for meeting future energy demands. In the last years, more attention has been focused on tertiary recovery techniques, known as Chemical Enhanced Oil Recovery (CEOR), to mobilize entrapped oil (Sen, 2008; Youssef et al., 2009; Brown, 2010).

Chemical methods include the use of surfactants, polymers, acids, gases and solvents (Lazar et al., 2007). Surfactants reduce the interfacial tension between oil-water and oil-rock interfaces, decreasing the capillary forces that prevent oil moving through the rock pores; they also alter the wettability of the reservoir rock. Polymers are used to increase the viscosity of water in waterflooding operations, enhancing the effectiveness of the process. Furthermore, polymers plug oil-depleted zones, directing the water-flood to oil-rich channels to release residual oil. Acids are used to increase the permeability through the porous network. Gases and solvents decrease oil viscosity and promote its flow; gases also increase the pressure in the reservoir. It is generally accepted that about $30 \%$ of the oil contained in the reservoirs can be recovered using current CEOR technology (Bordoloi and Konwar, 
2008). However, these processes are environmentally hazardous, expensive, and leave undesirable residues which are difficult to dispose of, without adversely affecting the environment.

Microbial Enhanced Oil Recovery (MEOR) is an important tertiary oil recovery technology that represents a cost-effective and eco-friendly alternative to CEOR. In MEOR, selected microbial strains are used to synthesize compounds analogous to those used in CEOR processes to increase the recovery of oil from depleted and marginal reservoirs, thereby extending their life. MEOR is a less expensive process when compared with CEOR because microorganisms can synthesize useful products by fermenting low-cost substrates or raw materials. Furthermore, microbial products are biodegradable and have low toxicity (Lazar et al., 2007; Suthar et al., 2008; Banat et al., 2010).

Biosurfactant MEOR represents one of the most promising methods to recover a substantial proportion of the residual oil from mature oil fields (Banat et al., 2010; Simpson et al., 2011). Biosurfactants are a heterogeneous group of surface-active molecules produced by microorganisms with both hydrophilic and hydrophobic domains, which allow them to partition at the interface between fluid phases with different degrees of polarity, such as oil-water or air-water interfaces. Due to these properties, biosurfactants reduce surface and interfacial tension and form stable emulsions where hydrocarbons can be solubilised in water, or water in hydrocarbons (Jenneman et al., 1983; Yakimov et al., 1995; Suthar et al., 2008; Banat et al., 2010). Biosurfactants produced by some microorganisms are capable of generating the low interfacial tension between the hydrocarbon and the aqueous phases required to mobilize entrapped oil (Yakimov et al., 1997; Youssef et al., 2007; Simpson et al., 2011). These compounds are good candidates for application in MEOR processes and can efficiently replace synthetic surfactants due to their specific activity, low toxicity, high biodegradability and effectiveness at extreme conditions of temperature, pressure, $\mathrm{pH}$ and salinity (Nitschke and Pastore, 2006; Abdel-Mawgoud et al., 2008; Bordoloi and Konwar, 2008; Pornsunthorntawee et al., 2008; Lotfabad et al., 2009).

There are two main strategies that can be adopted for the use of biosurfactants in enhanced oil recovery. Biosurfactants can be produced ex situ and subsequently injected into the reservoir; or they can be produced in situ by indigenous or injected microorganisms, stimulated by the addition of selected nutrients into the well. The first approach is expensive due to the capital required for bioreactor operation, product purification and introduction into oilcontaining rocks. The second option is more favourable from an economic point of view, but requires the use of microorganisms capable of producing sufficient amounts of biosurfactant within the reservoir (Lazar et al., 2007; Banat et al., 2010).

Another mechanism of MEOR is the use of microorganisms to degrade heavy oil fractions. As a result the oil viscosity decreases and it becomes more fluid, lighter and more valuable. In some cases, combining multiple mechanisms by using consortia of microorganisms with different properties (ability to degrade heavy oil fractions and biosurfactant production) may be an effective strategy for enhanced oil recovery (Jinfeng et al., 2005). There are a number of microorganisms able to degrade hydrocarbons using them as carbon sources (Wentzel et al., 2007). During the last decade interesting results for the microbial $n$-alkane degradation have been reported (Grishchenkov et al., 2000; Li et al., 2002; Sabirova et al., 2006; Etoumi et al., 2008; Binazadeh et al., 2009). In particular, strains of Gordonia amicalis have shown ability to degrade large $n$-alkanes under aerobic and anaerobic conditions (Hao et al., 2008); Pseudomonas fluorescens are capable of degrading hydrocarbons with chain lengths between C12 and C32 (Banat, 1995); heavier $n$-alkanes (C36-C40) can be degraded by Pseudomonas aeruginosa strains (Hasanuzzaman et al., 2007); and a thermophilic Bacillus strain that degraded long-chain (C15-C36) but not short-chain (C8-C14) n-alkanes (Wang et al., 2006) has been reported. The use of biosurfactant-producing indigenous Bacillus strains to degrade the higher fractions of crude oil and enhance its flow characteristics has also been studied for a petroleum reservoir in the Daqing Oilfield (She et al., 2011).

The main drawback of MEOR is the difficulty of isolating microorganisms that can grow and produce the desired metabolic products under the environmental conditions that usually exist in oil reservoirs; many reservoirs are anaerobic and have high salinities and temperatures. Since few environmental parameters of the reservoirs can be manipulated, this also limits the number of reservoirs where microorganisms can be used for in situ treatment. Bacillus subtilis and Bacillus licheniformis strains have been isolated repeatedly from oil reservoirs, thus presumably are able to tolerate the reservoir conditions (Jenneman et al., 1983; Yakimov et al., 1995; Dastgheib et al., 2008; Ghojavand et al., 2008a; Youssef et al., 2009; Simpson et al., 2011).

In this work, several microorganisms were isolated from crude oil samples and screened for anaerobic growth, biosurfactant production and ability to degrade heavy oil fractions, in order to obtain suitable candidates for application in MEOR.

\section{Materials and methods}

\subsection{Isolation of microorganisms from oil samples}

Crude oil samples obtained from four wells (W-3, W-8, W-9 and $\mathrm{W}-11$ ) of a Brazilian oil field were collected in sterile bottles. The temperature of the reservoir is about $40^{\circ} \mathrm{C}$. Samples were stored at room temperature until use. For isolation of microorganisms, two different methods were used. Direct isolation was performed by serially diluting crude oil samples, that were plated on agar solidified Bushnell-Hass medium and Raymond medium (containing $1 \%(\mathrm{v} / \mathrm{v}) n$-hexadecane as the sole carbon source), as well as Luria-Bertani (LB) medium. Plates were incubated both in aerobic and anaerobic conditions at different temperatures. Enrichment cultures were prepared in $500 \mathrm{ml}$ glass bottles containing $250 \mathrm{ml}$ of mineral media (Bushnell-Hass medium and Raymond medium) supplemented with $1 \%(\mathrm{v} / \mathrm{v}) n$-hexadecane as the sole carbon source. Crude oil samples $(5 \mathrm{ml})$ were transferred to the bottles and incubated at 37,42 and $50{ }^{\circ} \mathrm{C}$ for one month. To isolate bacterial strains, samples $(200 \mu \mathrm{l})$ of the enrichment cultures were periodically spread on agar plates that were incubated at 37,42 and $50{ }^{\circ} \mathrm{C}$ under aerobic and anaerobic conditions. After incubation, morphologically distinct colonies were re-isolated by transfer to fresh agar plates at least three times to obtain pure cultures. Isolate purity was verified through microscopic observation of Gram stained cultures. Pure cultures were stored at $-80^{\circ} \mathrm{C}$ in LB medium containing $20 \%(\mathrm{v} / \mathrm{v})$ glycerol solution.

The composition of Raymond medium was (g/l): $\mathrm{NaCl} 50.0$; $\mathrm{Na}_{2} \mathrm{HPO}_{4}$ 3.0; $\mathrm{NH}_{4} \mathrm{NO}_{3}$ 2.0; $\mathrm{KH}_{2} \mathrm{PO}_{4} 2.0$; yeast extract 0.5; $\mathrm{MgSO}_{4} \cdot 7 \mathrm{H}_{2} \mathrm{O} 0.2 ; \mathrm{Na}_{2} \mathrm{CO}_{3} 0.1 ; \mathrm{MnSO}_{4} \cdot 4 \mathrm{H}_{2} \mathrm{O} 0.02 ; \mathrm{CaCl}_{2} 0.01 ; \mathrm{FeSO}_{4}$ 0.01 ; supplemented with $1 \%(\mathrm{v} / \mathrm{v}) n$-hexadecane. The composition of Bushnell-Hass medium was (g/l): $\mathrm{KH}_{2} \mathrm{PO}_{4} 1.0 ; \mathrm{K}_{2} \mathrm{HPO}_{4} 1.0$; $\mathrm{NH}_{4} \mathrm{NO}_{3} \quad 1.0 ; \mathrm{MgSO}_{4} \cdot 7 \mathrm{H}_{2} \mathrm{O} 0.2 ; \mathrm{FeCl}_{3} 0.05 ; \mathrm{CaCl}_{2}$ 0.02; supplemented with $1 \%(\mathrm{v} / \mathrm{v}) n$-hexadecane. The composition of LB medium was (g/l): $\mathrm{NaCl} 10.0$; tryptone 10.0; yeast extract 5.0. All the media were adjusted to $\mathrm{pH}$ 7.0.

\subsection{Screening of biosurfactant-producing strains}

LB medium was used to study biosurfactant production by the different bacterial isolates. A single colony of each isolate was taken from the plate and transferred to $30 \mathrm{ml}$ of LB liquid medium; 
cultures were incubated at $40{ }^{\circ} \mathrm{C}$ and $120 \mathrm{rpm}$. Growth and biosurfactant production were examined under aerobic and anaerobic conditions. Anaerobic cultures were prepared removing oxygen by aseptically bubbling oxygen-free nitrogen into the flasks, which were sealed with rubber stoppers.

Samples were taken at different time points during the fermentation to determine biomass concentration and biosurfactant production. Bacterial growth was determined by measuring the optical density at $600 \mathrm{~nm}$. Afterwards, the samples were centrifuged $\left(10,000 \times \mathrm{g}, 20 \mathrm{~min}, 10^{\circ} \mathrm{C}\right)$ and cell-free supernatants were used to measure surface tension and emulsifying activity. At the end of the fermentation, cells were harvested by centrifugation and cell dry weight $(\mathrm{g} / \mathrm{l})$ was determined $\left(48 \mathrm{~h}\right.$ at $\left.105^{\circ} \mathrm{C}\right)$.

\subsection{Growth and biosurfactant production in mineral media}

The bacterial strains were grown in $30 \mathrm{ml}$ of different mineral media (medium E and Mineral Salt Solution (MSS) with and without $n$-hexadecane $(1 \%, \mathrm{v} / \mathrm{v}))$ at $40^{\circ} \mathrm{C}$. The composition of Medium E was (g/l): $\mathrm{NaCl} 50.0 ; \mathrm{K}_{2} \mathrm{HPO}_{4} 10.6$; sucrose $10.0 ; \mathrm{KH}_{2} \mathrm{PO}_{4}$ 5.3; $\left(\mathrm{NH}_{4}\right)_{2} \mathrm{SO}_{4} 1.0 ; \mathrm{MgSO}_{4} \cdot 7 \mathrm{H}_{2} \mathrm{O} 0.25$; supplemented with $1 \%(\mathrm{v} / \mathrm{v})$ of trace salt solution. Trace salt solution contained $(\mathrm{g} / \mathrm{l})$ : $\mathrm{MnSO}_{4} \cdot 4 \mathrm{H}_{2} \mathrm{O}$ 3.0; EDTA 1.0; $\mathrm{FeSO}_{4} \cdot 7 \mathrm{H}_{2} \mathrm{O} 0.1 ; \mathrm{CaCl}_{2} \cdot 2 \mathrm{H}_{2} \mathrm{O} 0.1$; $\mathrm{CoCl}_{2} \cdot 6 \mathrm{H}_{2} \mathrm{O} 0.1 ; \mathrm{ZnSO}_{4} \cdot 7 \mathrm{H}_{2} \mathrm{O} 0.1 ; \mathrm{CuSO}_{4} \cdot 5 \mathrm{H}_{2} \mathrm{O} 0.01 ; \mathrm{AlK}\left(\mathrm{SO}_{4}\right)_{2}$. $12 \mathrm{H}_{2} \mathrm{O} 0.01 ; \mathrm{H}_{3} \mathrm{BO}_{3} 0.01 ; \mathrm{Na}_{2} \mathrm{MoO}_{4} \cdot 2 \mathrm{H}_{2} \mathrm{O}$ 0.01. The Mineral Salt Solution consisted of $(\mathrm{g} / \mathrm{l})$ : $\mathrm{NaCl} 10.0$; sucrose 10.0; $\mathrm{Na}_{2} \mathrm{HPO}_{4}$ 5.0; $\mathrm{NH}_{4} \mathrm{NO}_{3}$ 2.0; $\mathrm{KH}_{2} \mathrm{PO}_{4} 2.0 ; \mathrm{MgSO}_{4} \cdot 7 \mathrm{H}_{2} \mathrm{O}$ 0.2. Both media were adjusted to $\mathrm{pH} 7.0$.

\subsection{Biosurfactant production and isolation}

Biosurfactant production was carried out in shake flasks containing $500 \mathrm{ml}$ of LB medium. Each flask was inoculated with $5 \mathrm{ml}$ of a pre-culture that was prepared using the same culture medium and incubated overnight at the optimum conditions established for each isolate. The flasks were then incubated at the same conditions until the stationary phase was reached. At the end of the fermentation, cells were harvested by centrifugation $(10,000 \times \mathrm{g}, 20 \mathrm{~min}$, $10{ }^{\circ} \mathrm{C}$ ) and cell dry weight $(\mathrm{g} / \mathrm{l})$ was determined $\left(48 \mathrm{~h}\right.$ at $\left.105^{\circ} \mathrm{C}\right)$. To recover the biosurfactant, the cell-free supernatant was subjected to acid precipitation. Briefly, the supernatant was adjusted to $\mathrm{pH}$ 2.0 with $\mathrm{HCl} 6 \mathrm{M}$ and left overnight at $4{ }^{\circ} \mathrm{C}$. Afterwards, the precipitate was collected by centrifugation $(10,000 \times \mathrm{g}, 20 \mathrm{~min}$, $4{ }^{\circ} \mathrm{C}$ ) and washed twice with acidified water ( $\left.\mathrm{pH} 2.0\right)$. The crude biosurfactant was dissolved in a minimal amount of demineralised water and the $\mathrm{pH}$ was adjusted to 7.0 using $\mathrm{NaOH} 1 \mathrm{M}$. Finally, the crude biosurfactant solution was freeze-dried and stored at $-20^{\circ} \mathrm{C}$ for further use.

\subsection{Surface-activity determination}

Surface tension measurements of culture broth supernatants and biosurfactant solutions were performed according to the Ring method described elsewhere (Gudiña et al., 2010). A KRÜSS K6 Tensiometer (KRÜSS GmbH, Hamburg, Germany) equipped with a $1.9 \mathrm{~cm}$ De Noüy platinum ring was used. To increase the accuracy of the surface tension measurements, an average of triplicates was determined. All the measurements were performed at room temperature $\left(20^{\circ} \mathrm{C}\right)$. Isolates which reduced the culture broth surface tension below $40 \mathrm{mN} / \mathrm{m}$ were considered as biosurfactant producers.

\subsection{Emulsifying activity determination}

Emulsifying activity was determined by the addition of $2 \mathrm{ml}$ of $n$-hexadecane to the same volume of cell-free culture broth supernatant or biosurfactant solution in glass test tubes. The tubes were mixed with vortex at high speed for $2 \mathrm{~min}$ and then incubated at $25{ }^{\circ} \mathrm{C}$ for $24 \mathrm{~h}$. The stability of the emulsion was determined after $24 \mathrm{~h}$, and the emulsification index $\left(E_{24}\right)$ was calculated as the percentage of the height of the emulsified layer $(\mathrm{mm})$ divided by the total height of the liquid column (mm). Emulsions formed by the different isolates were compared with those formed by a $1 \%$ $(\mathrm{w} / \mathrm{v})$ solution of the synthetic surfactant sodium dodecyl sulphate (SDS) in demineralised water, as proposed by Das et al. (1998). All emulsification indexes were performed in triplicate.

\subsection{Critical micelle concentration ( $\mathrm{cmc}$ )}

Critical micelle concentration is the concentration of an amphiphilic component in solution at which the formation of micelles is initiated. Concentrations ranging from 0.001 to $5 \mathrm{~g} / \mathrm{l}$ of the crude biosurfactants recovered from the different isolates were prepared in PBS $\left(10 \mathrm{mM} \mathrm{KH} \mathrm{KO}_{4} / \mathrm{K}_{2} \mathrm{HPO}_{4}\right.$ and $150 \mathrm{mM} \mathrm{NaCl}$ with $\mathrm{pH}$ adjusted to 7.0) and the surface tension of each sample was determined by the Ring method at room temperature $\left(20^{\circ} \mathrm{C}\right)$ as previously described. The $\mathrm{cmc}$ was determined by plotting the surface tension as a function of the logarithm of biosurfactant concentration and it was found at the point of intersection between the two lines that best fit through the pre- and post-cmc data. All measurements were done in triplicate.

\subsection{Identification of the isolates}

Bacterial isolates that displayed high biosurfactant production were selected and identified by partial 16S rRNA sequencing. The $16 \mathrm{~S}$ rRNA gene was amplified by PCR using primers 341F and 907R. The resulting sequences were compared with sequences in the GenBank database of the National Center for Biotechnology Information (NCBI) (http://www.ncbi.nlm.nih.gov) using the nucleotide-nucleotide blast (BLASTn) network service, to determine their phylogenetic affiliations.

\subsection{Stability studies}

The effect of several environmental parameters on the activity of biosurfactants produced by the different isolates was determined. Stability studies were performed using the cell-free broth obtained by centrifuging the cultures at $10,000 \times g$ for $20 \mathrm{~min}$. In order to assess the effect of salinity on biosurfactant activity, the culture broth supernatants were supplemented with different $\mathrm{NaCl}$ concentrations (from 10 to $200 \mathrm{~g} / \mathrm{l}$ ) and the surface tension was measured as described above. To evaluate the stability of the biosurfactants to high temperatures, broth samples were incubated at $121^{\circ} \mathrm{C}$ for $20 \mathrm{~min}$ and allowed to cool to room temperature. Surface tension and emulsification indexes were measured and compared to the corresponding values before heat treatment. The $\mathrm{pH}$ stability was studied by adjusting the cell-free broth to different $\mathrm{pH}$ values (2.0-13.0) using $\mathrm{HCl}$ or $\mathrm{NaOH}$ solutions, and then surface tension values were measured as described above. All the experiments were carried out in triplicate.

\subsection{Growth at different temperatures and salinities}

In addition to the lack of oxygen, temperature and salinity appear to be the most important environmental factors that influence bacterial growth in the reservoir. Therefore, media containing different $\mathrm{NaCl}$ concentrations $(0-200 \mathrm{~g} / \mathrm{l})$ were used to grow the isolated bacteria and cultures were incubated at temperatures ranging from $40^{\circ} \mathrm{C}$ to $60^{\circ} \mathrm{C}$ for different time intervals. 


\subsection{Hydrocarbon degradation determination}

The ability of the isolated microorganisms to degrade paraffinic mixtures under aerobic and anaerobic conditions was evaluated using two different experimental conditions. In the first experimental condition studied, YP medium supplemented with a paraffinic mixture A (containing $n$-alkanes between C14-C24) was used. In the second condition, Mineral Salt Medium (MSM) and a heavier paraffinic mixture B (containing $n$-alkanes between $\mathrm{C} 20-\mathrm{C} 30$ ) were used. The mixture $A$ was prepared in order to make a preliminary assessment of the degradation ability of 5 different strains. The mixture B was prepared in order to evaluate the ability of 6 different strains to degrade heavier $n$-alkanes chains under anaerobic conditions, aiming at their potential application on Microbial Enhanced Oil Recovery.

The composition of YP medium was $(\mathrm{g} / \mathrm{l})$ : peptone 20.0; yeast extract 10.0. The MSM contained $(\mathrm{g} / \mathrm{l}): \mathrm{KH}_{2} \mathrm{PO}_{4}$ 4.7; $\mathrm{KNO}_{3} 4.0$; $\mathrm{MgSO}_{4} \cdot 7 \mathrm{H}_{2} \mathrm{O}$ 1.0; $\mathrm{Na}_{2} \mathrm{HPO}_{4}$ 0.119; $\mathrm{FeSO}_{4} \cdot 7 \mathrm{H}_{2} \mathrm{O} 0.015 ; \mathrm{CaCl}_{2} \cdot 2 \mathrm{H}_{2} \mathrm{O}$ $0.01 ; \mathrm{MnCl}_{2} \cdot 4 \mathrm{H}_{2} \mathrm{O} 0.01$. MSM was used to evaluate the degradation of $n$-alkanes by the different isolates in medium without additional carbon sources, since YP medium contains peptone and yeast extract, which can be used as carbon sources by the microorganisms.

Flasks containing $50 \mathrm{ml}$ of each culture media supplemented with $10 \%(\mathrm{w} / \mathrm{v})$ of the respective sterile paraffinic mixture were prepared. The flasks were sealed with rubber stoppers. Anaerobic cultures were prepared removing oxygen by aseptically bubbling oxygen-free nitrogen into the flasks. The paraffinic mixture A was composed by a ratio of 3:1 of two synthetic liquid paraffins, RT20 and RT31, obtained from Rubitherm (Rubitherm $\mathrm{GmbH}$, Berlin, Germany). Culture media were supplemented with $1 \%(\mathrm{w} / \mathrm{v})$ of squalane (Sigma-Aldrich Co., St. Louis, USA), in order to evaluate the ability of the strains to degrade ramified hydrocarbons. The mixture B was prepared with $23 \%(\mathrm{w} / \mathrm{w})$ of solid paraffin wax with a melting point of $50-52{ }^{\circ} \mathrm{C}$ (purchased from Sigma-Aldrich), dissolved in dodecane ( $99 \%$ of purity, also from Sigma-Aldrich). Cultures were performed at $40^{\circ} \mathrm{C}$ and $150 \mathrm{rpm}$ during 4 days under aerobic conditions, and during 15 days in anaerobic conditions. Control flasks were incubated at the same conditions without addition of microorganisms.

After the incubation time, the organic phase was separated and diluted $(20 \mathrm{mg} / \mathrm{ml})$ in dichloromethane for gas chromatography (GC) analysis. GC analysis of each sample was performed with $\mathrm{CP}$ 3800 Varian gas Chromatograph equipped with and on-column injection, FID detector, and DB-5HT capillary column ( $30 \mathrm{~m} \times 0.32 \mathrm{~mm}$ i.d., $0.1 \mu \mathrm{m}$ thickness) (J\&W Scientific Inc., California, USA). Helium was used as gas carrier and a constant flow rate of $2 \mathrm{ml} / \mathrm{min}$ was set. Injector and detector temperatures were 350 and $370{ }^{\circ} \mathrm{C}$, respectively. Oven temperature was set at $50^{\circ} \mathrm{C}$ during $1 \mathrm{~min}$, raised to $350{ }^{\circ} \mathrm{C}$ at the rate of $10^{\circ} \mathrm{C} / \mathrm{min}$, and at last kept at $370{ }^{\circ} \mathrm{C}$ during $1 \mathrm{~min}$. All the samples were analyzed in triplicate.

\section{Results and discussion}

\subsection{Isolation of microorganisms from oil samples}

When petroleum samples were spread on agar plates and incubated at different temperatures, no isolates were obtained, neither under aerobic nor anaerobic conditions. However, using the enrichment method, a total of fifty-eight bacterial strains were recovered. Results obtained are summarized in Table 1.

\subsection{Screening of biosurfactant-producing strains}

The different isolates were screened for extracellular biosurfactant production in LB medium under aerobic and anaerobic
Table 1

Number of isolates obtained from the different oil samples at different temperatures and results obtained regarding biosurfactant production from the screening process under aerobic and anaerobic conditions.

\begin{tabular}{|c|c|c|c|c|c|c|}
\hline \multirow[t]{2}{*}{ Sample } & \multicolumn{4}{|c|}{ Number of isolates } & \multicolumn{2}{|c|}{ Biosurfactant production } \\
\hline & $37^{\circ} \mathrm{C}$ & $42^{\circ} \mathrm{C}$ & $50^{\circ} \mathrm{C}$ & Total & Aerobic & Anaerobic \\
\hline W-3 & 3 & 3 & 14 & 20 & 8 & 2 \\
\hline W-8 & 3 & 11 & 7 & 21 & 12 & 0 \\
\hline W-9 & 2 & 3 & 3 & 8 & 2 & 0 \\
\hline W-11 & 2 & 1 & 6 & 9 & 8 & 3 \\
\hline Total & 10 & 18 & 30 & 58 & 30 & 5 \\
\hline
\end{tabular}

conditions at $40^{\circ} \mathrm{C}$. To evaluate biosurfactant production, both surface tension and emulsifying activity were taken into account. However, only those isolates that reduced surface tension were found to exhibit emulsifying activity (no bioemulsifier production was detected). Under aerobic conditions, thirty of the fifty-eight isolates reduced the culture medium surface tension below $40 \mathrm{mN} / \mathrm{m}$, and therefore were considered biosurfactant producers. From these, only five isolates produced biosurfactants also under anaerobic conditions (Table 1 ). The most relevant results obtained are shown in Table 2.

Biosurfactants produced by isolates \#111 and \#902 showed the highest emulsifying activity against $n$-hexadecane, similar to the one obtained with the synthetic surfactant SDS. However, surface tension values obtained with those isolates were not as low as the obtained with other isolates. Furthermore, although isolates \#111 and \#902 grew at anaerobic conditions, no surface tension reduction or emulsifying activity could be observed, which hampers their application in MEOR processes in situ, since most oil reservoirs are anaerobic. The other isolates described in Table 2 produced biosurfactants under both aerobic and anaerobic conditions. However, biomass and biosurfactant production were higher under aerobic conditions for all the isolates, which is in agreement with the results obtained by other authors (Yakimov et al., 1995, 1997; Dastgheib et al., 2008; Ghojavand et al., 2008a). Isolates \#309, \#311 and \#573 showed the highest surface activity, reducing the surface tension of the culture broth from $51.3 \mathrm{mN} / \mathrm{m}$ to values around $30 \mathrm{mN} / \mathrm{m}$, and emulsified $n$-hexadecane similarly to SDS. Isolates \#309 and \#311 were identified as the best biosurfactant producers under anaerobic conditions. Furthermore, emulsions formed by supernatants obtained from isolates \#111, \#309, \#311, \#573 and \#902 remained stable for two weeks at $25^{\circ} \mathrm{C}$.

\subsection{Identification of the isolates}

The isolates described in Table 2 were identified according to the partial sequence obtained from their 16S rRNA genes. The sequences obtained were compared with those described in databases. The partial sequence of 16S rRNA genes from isolates \#111 and \#902 showed $100 \%$ similarity with $P$. aeruginosa. The partial sequence of $16 \mathrm{~S}$ rRNA genes of the remaining isolates showed $100 \%$ similarity with $B$. subtilis. The sequences were deposited in the Gen Bank database under accession numbers JQ281104-JQ281110.

\subsection{Study of biosurfactant production in mineral media}

The isolates presenting the best results regarding biosurfactant production in LB medium were then evaluated under anaerobic conditions using Mineral Salt Solution (MSS), Mineral Salt Solution supplemented with $1 \%(\mathrm{v} / \mathrm{v}) n$-hexadecane (MSSH) and medium E. The results obtained are gathered in Table 3. As can be seen from these results, the MSS (with and without $n$-hexadecane) offered better results than medium $\mathrm{E}$ for all the isolates. Addition of 
Table 2

Surface tension values $(\mathrm{mN} / \mathrm{m})$, emulsification indexes $\left(E_{24}, \%\right)$ and biomass concentrations $(\mathrm{g} / \mathrm{l})$ obtained with the different isolates grown aerobically and anaerobically in LB medium at $40{ }^{\circ} \mathrm{C}$. Surface tension values were determined six times at room temperature $\left(20^{\circ} \mathrm{C}\right)$. Emulsification indexes were calculated three times at $25^{\circ} \mathrm{C}$. Biomass concentration was calculated as dry weight $\left(105^{\circ} \mathrm{C}, 48 \mathrm{~h}\right)$. Results represent the average of three independent experiments \pm standard deviation.

\begin{tabular}{|c|c|c|c|c|c|c|}
\hline \multirow[t]{2}{*}{ Strain } & \multicolumn{3}{|l|}{ Aerobic } & \multicolumn{3}{|l|}{ Anaerobic } \\
\hline & $\mathrm{ST}(\mathrm{mN} / \mathrm{m})$ & $E_{24}(\%)$ & [Biomass] (g/l) & $\mathrm{ST}(\mathrm{mN} / \mathrm{m})$ & $E_{24}(\%)$ & [Biomass] $(\mathrm{g} / \mathrm{l})$ \\
\hline$\# 111$ & $34.1 \pm 0.6$ & $56.5 \pm 0.0$ & $1.315 \pm 0.346$ & $53.7 \pm 4.9$ & $0.0 \pm 0.0$ & $0.363 \pm 0.138$ \\
\hline \#191 & $31.0 \pm 1.1$ & $52.3 \pm 2.4$ & $1.364 \pm 0.467$ & $35.7 \pm 1.5$ & $2.6 \pm 4.1$ & $0.195 \pm 0.050$ \\
\hline \#309 & $29.9 \pm 0.1$ & $51.6 \pm 1.4$ & $0.709 \pm 0.252$ & $31.0 \pm 1.3$ & $22.9 \pm 11.7$ & $0.218 \pm 0.097$ \\
\hline \#311 & $30.1 \pm 0.4$ & $50.8 \pm 0.0$ & $0.365 \pm 0.110$ & $31.0 \pm 1.3$ & $22.7 \pm 9.4$ & $0.246 \pm 0.041$ \\
\hline \#552 & $32.0 \pm 0.2$ & $46.1 \pm 12.3$ & $1.373 \pm 0.379$ & $35.4 \pm 1.3$ & $3.0 \pm 3.7$ & $0.207 \pm 0.060$ \\
\hline \#573 & $30.5 \pm 0.5$ & $52.3 \pm 1.5$ & $1.686 \pm 0.648$ & $36.0 \pm 2.4$ & $2.2 \pm 3.5$ & $0.178 \pm 0.041$ \\
\hline \#902 & $36.1 \pm 0.6$ & $56.5 \pm 0.0$ & $1.328 \pm 0.011$ & $56.0 \pm 3.6$ & $0.0 \pm 0.0$ & $0.413 \pm 0.144$ \\
\hline LB & $51.3 \pm 0.5$ & $0.0 \pm 0.0$ & - & $51.3 \pm 0.5$ & $0.0 \pm 0.0$ & - \\
\hline SDS $1 \%$ & $39.9 \pm 0.4$ & $55.0 \pm 1.7$ & - & $39.9 \pm 0.4$ & $55.0 \pm 1.6$ & - \\
\hline
\end{tabular}

$n$-hexadecane to the culture broth was found to promote a higher biosurfactant production by some isolates and had no effect on the others. None of the isolates was able to grow or produce biosurfactants in MSS using $n$-hexadecane as the sole carbon source (data not shown). The lowest surface tension values (around $30 \mathrm{mN} / \mathrm{m}$ ) were obtained by isolates \#309, \#311 and \#573, with emulsifying indexes between $24 \%$ and $34 \%$.

Several $P$. aeruginosa strains have been recovered from petroleum samples and oil contaminated places, and their biosurfactants exhibit good characteristics for application in MEOR, as demonstrated by simulations performed in sand-pack columns (Bordoloi and Konwar, 2008; Pornsunthorntawee et al., 2008; Lotfabad et al., 2009). However, those isolates were studied under aerobic conditions and the biosurfactants were produced ex situ. Therefore, although the authors suggested their possible use in MEOR, these strains are not appropriate for use in oil reservoirs. Most of the microorganisms that are potentially useful for application in MEOR in situ belong to the genus Bacillus. Bacillus mojavensis JF-2, a thermotolerant and halotolerant strain isolated from an oil field by Jenneman and collaborators (1983), grows and produces similar amounts of a lipopeptide biosurfactant under both aerobic and anaerobic conditions, reducing the surface tension of the medium below $30 \mathrm{mN} / \mathrm{m}$, and additionally it is not inhibited by crude oil (Jenneman et al., 1983; Javaheri et al., 1985). Other strains isolated from oil fields and which applicability in MEOR has been demonstrated are B. licheniformis BAS50 (Yakimov et al., 1995, 1997), B. licheniformis ACO1 (Dastgheib et al., 2008) and B. subtilis PTCC1696 (Ghojavand et al., 2008a). Biosurfactants produced by those microorganisms recovered $22-60 \%$ of the residual oil entrapped in sand-packed columns (Yakimov et al., 1997; Dastgheib et al., 2008; Pornsunthorntawee et al., 2008; Suthar et al., 2008). Furthermore, Youssef et al. (2007) demonstrated that inoculation of oil wells with Bacillus strains and nutrients is possible, and that biosurfactants can be produced in situ at concentrations that are sufficient to mobilize significant amount of residual oil. Taking into account these data and the results obtained with isolates \#309, \#311 and \#573 regarding biosurfactant production, they can be considered good candidates for application in MEOR.

\subsection{Growth at different temperatures and salinities}

Growth at several temperatures and salinities was evaluated for the different isolates in solid and liquid medium. B. subtilis isolates (\#191, \#309, \#311, \#552 and \#573) were able to grow at temperatures between 40 and $55^{\circ} \mathrm{C}$ in solid medium. At $45^{\circ} \mathrm{C}$ they grew at $\mathrm{NaCl}$ concentrations up to $100 \mathrm{~g} / \mathrm{l}$. Isolates \#309 and \#311 grew at $50{ }^{\circ} \mathrm{C}$ in liquid medium, and biosurfactant production was similar to the obtained at $40{ }^{\circ} \mathrm{C}$. However, isolates \#191, \#552 and \#573 were unable to grow in liquid medium at temperatures higher than $45^{\circ} \mathrm{C}$. Similar results with several Bacillus strains have been reported by other authors (Jenneman et al., 1983; Javaheri et al., 1985; Yakimov et al., 1995, 1997; Dastgheib et al., 2008; Ghojavand et al. 2008a). For $P$. aeruginosa isolates \#111 and \#902 no growth was observed at temperatures higher than $42{ }^{\circ} \mathrm{C}$ neither in liquid or solid media.

\subsection{Hydrocarbon degradation}

Although the use of Bacillus strains for biosurfactant production has been widely described in the literature, their use to degrade $n$ alkanes has seldom been addressed. In order to evaluate the ability of the isolated $B$. subtilis strains to degrade $n$-alkanes, two different paraffinic mixtures (A and B) were used. The mixture A was incubated with isolates \#191, \#551, \#571, \#572 and \#573 under aerobic and anaerobic conditions. The respective variations of relative weight fraction of each $n$-alkane present in mixture A compared with the control sample (incubated at the same conditions without microorganisms) are illustrated in Figs. 1 and 2.

The isolates studied were found to be able to grow in YP medium supplemented with paraffinic mixture A, both under

Table 3

Surface tension values $(\mathrm{mN} / \mathrm{m})$, emulsification indexes $\left(E_{24}, \%\right)$ and biomass concentrations $(\mathrm{g} / \mathrm{l})$ obtained with the different isolates grown in different media for $120 \mathrm{~h}$ at $40{ }^{\circ} \mathrm{C}$ and $120 \mathrm{rpm}$ under anaerobic conditions. Surface tension values were determined six times at room temperature $\left(20^{\circ} \mathrm{C}\right)$. Emulsification indexes were calculated three times at $25^{\circ} \mathrm{C}$. Biomass concentration was calculated as dry weight $\left(105^{\circ} \mathrm{C}, 48 \mathrm{~h}\right)$. Results represent the average of three independent experiments \pm standard deviation.

\begin{tabular}{|c|c|c|c|c|c|c|c|c|c|}
\hline \multirow[t]{2}{*}{ Strain } & \multicolumn{3}{|l|}{ MSS } & \multicolumn{3}{|l|}{ MSSH } & \multicolumn{3}{|l|}{ Medium E } \\
\hline & $\mathrm{ST}(\mathrm{mN} / \mathrm{m})$ & $E_{24}(\%)$ & [Biomass] (g/l) & $\mathrm{ST}(\mathrm{mN} / \mathrm{m})$ & $E_{24}(\%)$ & [Biomass] (g/l) & $\mathrm{ST}(\mathrm{mN} / \mathrm{m})$ & $E_{24}(\%)$ & [Biomass] (g/l) \\
\hline \#191 & $41.7 \pm 1.2$ & $14.6 \pm 1.9$ & $0.194 \pm 0.062$ & $40.0 \pm 2.0$ & $13.3 \pm 5.9$ & $0.176 \pm 0.055$ & $50.5 \pm 1.9$ & $11.7 \pm 2.1$ & $0.188 \pm 0.071$ \\
\hline \#309 & $31.4 \pm 1.3$ & $25.9 \pm 4.2$ & $0.221 \pm 0.050$ & $31.4 \pm 0.5$ & $24.6 \pm 5.3$ & $0.196 \pm 0.068$ & $32.2 \pm 1.5$ & $28.9 \pm 2.7$ & $0.193 \pm 0.033$ \\
\hline \#311 & $30.5 \pm 0.1$ & $8.5 \pm 4.0$ & $0.245 \pm 0.076$ & $31.0 \pm 0.6$ & $34.2 \pm 3.9$ & $0.191 \pm 0.042$ & $36.4 \pm 1.3$ & $8.0 \pm 2.8$ & $0.175 \pm 0.035$ \\
\hline \#552 & $48.6 \pm 1.7$ & $13.4 \pm 1.6$ & $0.263 \pm 0.087$ & $41.5 \pm 1.9$ & $14.1 \pm 5.6$ & $0.238 \pm 0.008$ & $56.3 \pm 0.9$ & $10.2 \pm 4.8$ & $0.160 \pm 0.051$ \\
\hline \#573 & $31.5 \pm 0.4$ & $24.9 \pm 2.3$ & $0.284 \pm 0.057$ & $33.7 \pm 1.4$ & $19.4 \pm 5.6$ & $0.217 \pm 0.073$ & $43.2 \pm 1.2$ & $16.9 \pm 7.5$ & $0.230 \pm 0.071$ \\
\hline Control & $66.4 \pm 1.5$ & $0.0 \pm 0.0$ & - & $63.3 \pm 0.9$ & $0.0 \pm 0.0$ & - & $65.6 \pm 0.8$ & $0.0 \pm 0.0$ & - \\
\hline SDS 1\% & $39.9 \pm 0.4$ & $55.0 \pm 1.7$ & - & $39.9 \pm 0.4$ & $55.0 \pm 1.7$ & - & $39.9 \pm 0.4$ & $55.0 \pm 1.7$ & - \\
\hline
\end{tabular}




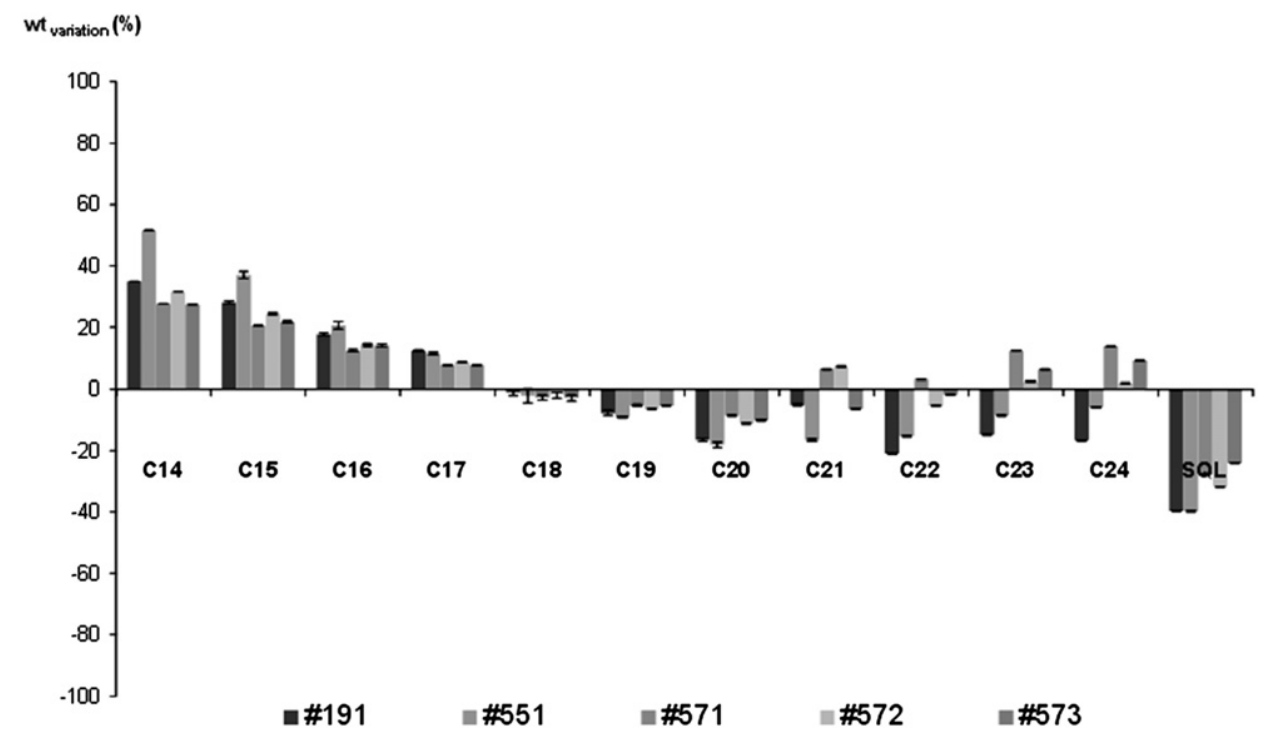

Fig. 1. Variation of relative weight fraction of $n$-alkanes present in paraffinic mixture A after incubation with bacterial isolates, for 4 days at $40{ }^{\circ} \mathrm{C}$ and aerobic conditions as compared to the control. (SQL: squalane).

aerobic and anaerobic conditions. The increase observed in the relative weight fraction of $n$-alkanes lower than $\mathrm{C} 18$ and the decrease observed in the percentage of $n$-alkanes between $\mathrm{C} 18$ and C20 after treatment with isolates \#191, \#551, \#571, \#572 and \#573 indicate that those isolates degraded $n$-alkanes between $\mathrm{C} 18$ and C20 into lighter ones, both under aerobic and anaerobic conditions. In presence of oxygen, isolates \#191 and \#551 were able to degrade also $n$-alkanes higher than C20. Comparing the influence of oxygen on degradation of $n$-alkanes by the different isolates, significant differences were only observed for isolates \#191 and \#571. Isolate \#191 showed a higher ability to degrade the long-chain $n$-alkanes (C18-C24) under aerobic conditions; however in absence of oxygen it was only able to degrade $n$-octadecane and $n$-nonadecane. On other hand, isolate \#571 exhibited an opposite behaviour and better results were obtained under anaerobic conditions. For the remaining isolates, similar degradation values were obtained in both conditions. The experiments also showed that all the isolates were able to degrade ramified hydrocarbons (squalane) either with or without oxygen.

In view of the positive results obtained, the authors decided to study the anaerobic degradation in a mineral medium where the hydrocarbons were the only available carbon source. Furthermore, aiming at extending the range of $n$-alkanes studied a new mixture $B$ containing $n$-alkanes up to C30 was used. It was observed that B. subtilis isolates \#191, \#309, \#316, \#551, \#552 and \#572 degraded the higher $n$-alkanes ( $>$ C27) under anaerobic conditions, and the percentage of $n$-alkanes with chains containing less than 25 carbons increased relatively to the control sample as shown in Fig. 3. The best results were obtained with isolates \#191, \#309 and \#552.

The ability of a thermophilic Bacillus strain to degrade $n$ alkanes ranging from C15 to C36, but not those lower than C14

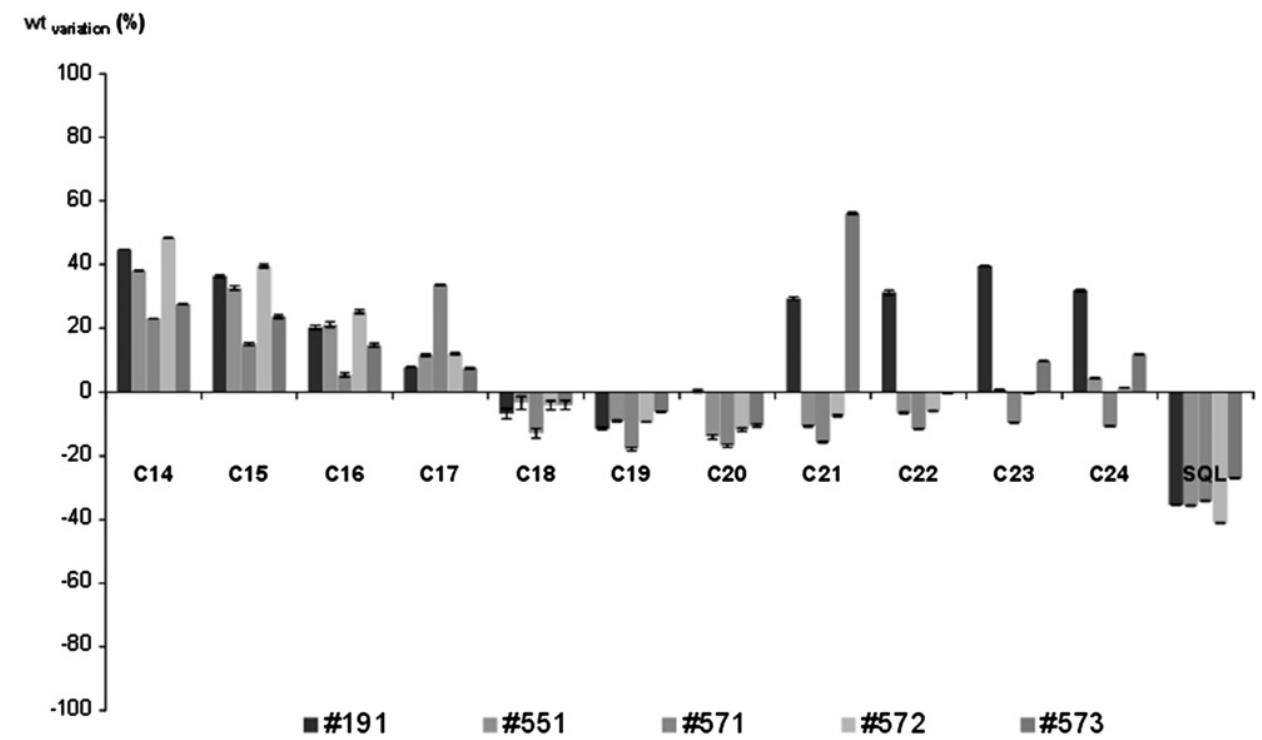

Fig. 2. Variation of relative weight fraction of $n$-alkanes present in paraffinic mixture A after incubation with bacterial isolates, for 15 days at $40{ }^{\circ} \mathrm{C}$ and anaerobic conditions as compared to the control. 


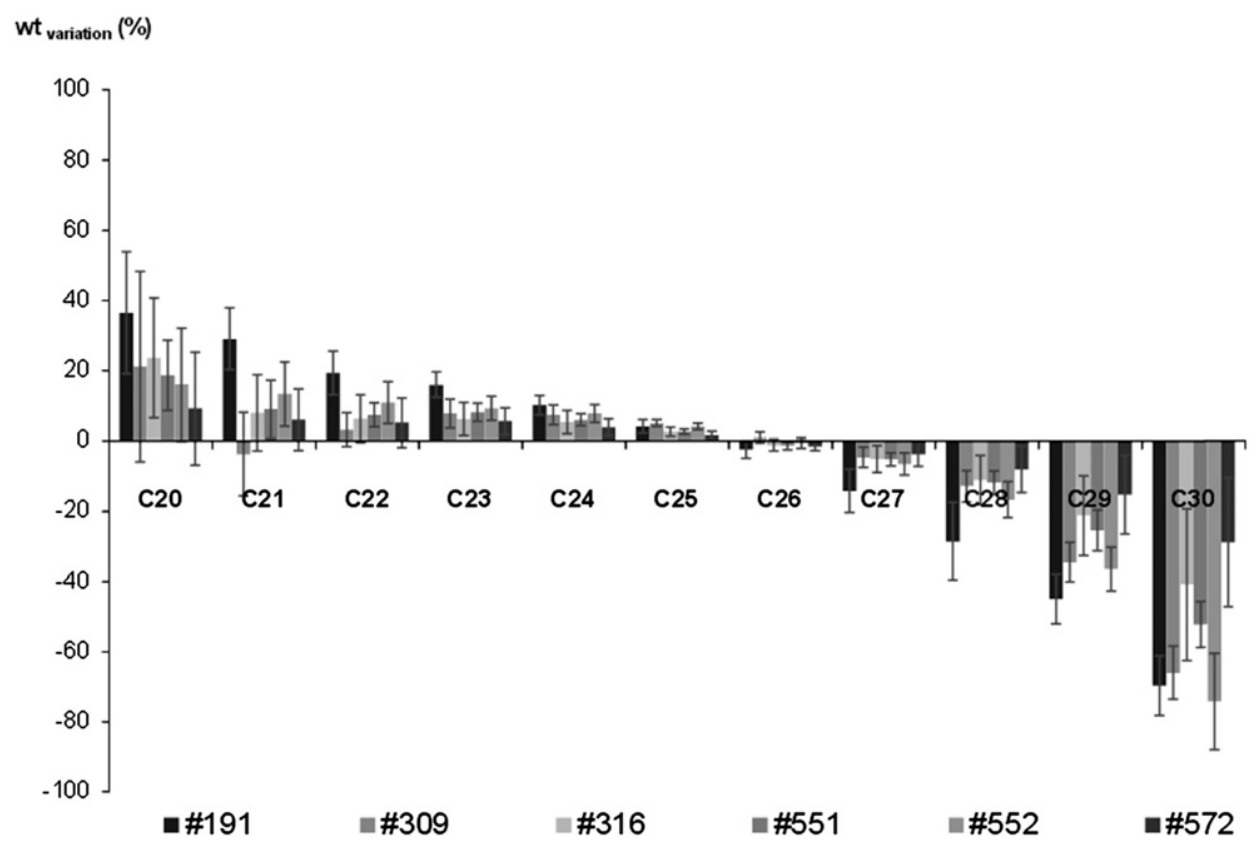

Fig. 3. Variation of relative weight fraction of $n$-alkanes present in paraffinic mixture B after incubation with bacterial isolates for 15 days, at $40{ }^{\circ} \mathrm{C}$ and anaerobic conditions as compared to the control.

was observed by Wang et al. (2006). She et al. (2011) observed the degradation of $n$-alkanes between C14 and C26 by three Bacillus strains isolated from an oil field. Moreover, Kato et al. (2001) isolated two Bacillus thermoleovorans strains from a petroleum reservoir which degraded $n$-alkanes between $\mathrm{C} 12$ and C30. Das and Mukherjee (2007) also observed that B. subtilis DM-04 preferentially degraded crude oil $n$-alkanes between C14 and C30. However, those assays were performed in aerobic conditions. G. amicalis LH3 utilizes a wide range of long-chain $n$-alkanes (C18-C36), although under aerobic conditions degraded preferentially $n$-alkanes between C18 and C24, whereas under anaerobic conditions degraded higher $n$-alkanes (C34-C36) (Hao et al., 2008). In MEOR processes, the degradation of long-chain $n$-alkanes under anaerobic conditions is a very important tool, since most of the oil reservoirs are anaerobic. Isolates \#191, \#309 and \#552 showed the ability to degrade $n$-alkanes with chains higher than C27 into lighter ones under anaerobic conditions, which can be applied to improve the flow properties of crude oil. Furthermore, isolates \#191 and \#309 additionally showed biosurfactant production under anaerobic conditions, thus suggesting those isolates as attractive candidates for application in MEOR.

\section{Table 4}

Surface tension values $(\mathrm{mN} / \mathrm{m})$, emulsification indexes $\left(E_{24}, \%\right)$ and critical micelle concentrations $(\mathrm{g} / \mathrm{l})$, obtained with freeze-dried biosurfactants from the different isolates dissolved in PBS ( $\mathrm{pH}$ 7.0). Samples were prepared with a concentration of $1 \mathrm{~g} / \mathrm{l}$ for $B$. subtilis isolates and $5 \mathrm{~g} / \mathrm{l}$ for $P$. aeruginosa isolates. Surface tension values were determined six times at room temperature $\left(20^{\circ} \mathrm{C}\right)$. Emulsification indexes were calculated three times at $25^{\circ} \mathrm{C}$. Results represent the average of three independent experiments \pm standard deviation.

\begin{tabular}{llll}
\hline Isolate & $\mathrm{ST}(\mathrm{mN} / \mathrm{m})$ & $E_{24}(\%)$ & $\mathrm{cmc}(\mathrm{g} / \mathrm{l})$ \\
\hline$\# 111$ & $35.5 \pm 0.1$ & $53.7 \pm 0.0$ & 2.3 \\
$\# 191$ & $32.8 \pm 0.2$ & $34.8 \pm 1.9$ & 0.13 \\
$\# 309$ & $30.4 \pm 0.2$ & $50.8 \pm 3.6$ & 0.02 \\
$\# 311$ & $30.3 \pm 0.3$ & $51.3 \pm 4.1$ & 0.02 \\
$\# 552$ & $32.0 \pm 0.3$ & $31.1 \pm 2.0$ & 0.10 \\
$\# 573$ & $31.2 \pm 0.2$ & $43.3 \pm 1.6$ & 0.03 \\
$\# 902$ & $37.9 \pm 0.1$ & $52.3 \pm 0.0$ & 2.3 \\
\hline
\end{tabular}

\subsection{Critical micelle concentration ( $\mathrm{cmc}$ )}

Freeze-dried biosurfactants obtained from the different isolates were dissolved in PBS ( $\mathrm{pH} 7.0)$ at a concentration of $1 \mathrm{~g} / \mathrm{l}$ for $B$. subtilis isolates, and $5 \mathrm{~g} / \mathrm{l}$ for $P$. aeruginosa strains, and surface tension, as well as emulsifying activity were determined. As can be seen from Table 4, the lowest surface tension values were obtained with isolates \#309 and \#311; those isolates also showed the highest emulsifying activities, except for the isolates \#111 and \#902 (but in this case, biosurfactant concentration was five times higher). To obtain the $\mathrm{cmc}$, the original concentrations were serially diluted with PBS buffer and the surface tension was determined. The effective concentration of biosurfactants from B. subtilis isolates was found to be much lower than that of biosurfactants from $P$. aeruginosa strains, with $\mathrm{cmc}$ values $20-100$ times lower. The lowest $\mathrm{cmc}$ values $(0.02 \mathrm{~g} / \mathrm{l})$ corresponded to isolates \#309 and \#311, with a minimum surface tension value of $30 \mathrm{mN} / \mathrm{m}$.

Lipopeptide biosurfactants produced by Bacillus strains include, among others, surfactin and lichenysin, which reduce surface tension to values around $26-36 \mathrm{mN} / \mathrm{m}$, with $\mathrm{cmc}$ values from 0.01 to $0.04 \mathrm{~g} / \mathrm{l}$, and emulsification indexes of about $60 \%$ (Javaheri et al., 1985; Yakimov et al., 1995; Nitschke and Pastore, 2006; AbdelMawgoud et al., 2008; Ghojavand et al., 2008b;

Table 5

Effect of $\mathrm{NaCl}$ concentration on surface activity. Surface tension values $(\mathrm{mN} / \mathrm{m}$ ) obtained with culture broth supernatants at different $\mathrm{NaCl}$ concentrations $(10-200 \mathrm{~g} / \mathrm{l})$. Surface tension values were determined six times at room temperature $\left(20^{\circ} \mathrm{C}\right)$. Results are expressed as means \pm standard deviations of three independent measurements.

\begin{tabular}{llllll}
\hline Isolate & $\mathrm{NaCl}(\mathrm{g} / \mathrm{l})$ & & \\
\cline { 2 - 5 } & 10 & 50 & 100 & 150 & 200 \\
\cline { 2 - 6 } & & & $\mathrm{ST}(\mathrm{mN} / \mathrm{m})$ \\
\hline$\# 191$ & $30.8 \pm 0.2$ & $28.5 \pm 0.1$ & $29.4 \pm 0.4$ & $38.0 \pm 4.1$ & $49.5 \pm 2.3$ \\
$\# 309$ & $29.6 \pm 0.2$ & $27.0 \pm 0.0$ & $27.8 \pm 0.1$ & $31.5 \pm 1.4$ & $37.4 \pm 0.5$ \\
$\# 311$ & $29.8 \pm 0.1$ & $27.0 \pm 0.0$ & $27.9 \pm 0.2$ & $31.2 \pm 0.2$ & $38.8 \pm 0.8$ \\
$\# 552$ & $31.4 \pm 0.1$ & $29.0 \pm 0.1$ & $30.6 \pm 0.3$ & $45.0 \pm 3.9$ & $51.5 \pm 0.7$ \\
$\# 573$ & $30.6 \pm 0.1$ & $28.1 \pm 0.1$ & $30.1 \pm 0.3$ & $42.4 \pm 4.4$ & $47.7 \pm 0.8$ \\
\hline
\end{tabular}


Table 6

Effect of $\mathrm{pH}$ on surface activity. Surface tension values $(\mathrm{mN} / \mathrm{m})$ obtained with culture broth supernatants at different $\mathrm{pH}$ values. Surface tension values were determined six times at room temperature $\left(20^{\circ} \mathrm{C}\right)$. Results are expressed as the means \pm standard deviations of three independent experiments.

\begin{tabular}{|c|c|c|c|c|c|c|}
\hline \multirow[t]{3}{*}{ Isolate } & \multicolumn{6}{|l|}{$\mathrm{pH}$} \\
\hline & 2.0 & 3.0 & 4.0 & 5.0 & 6.0 & 7.0 \\
\hline & & & \multicolumn{4}{|l|}{$\mathrm{ST}(\mathrm{mN} / \mathrm{m})$} \\
\hline \#191 & $56.2 \pm 2.3$ & $49.7 \pm 3.4$ & $38.9 \pm 1.6$ & $30.8 \pm 0.1$ & $29.0 \pm 0.1$ & $30.9 \pm 0.3$ \\
\hline \#309 & $60.0 \pm 2.0$ & $54.6 \pm 1.8$ & $43.8 \pm 4.0$ & $31.8 \pm 0.1$ & $27.5 \pm 0.1$ & $29.8 \pm 0.1$ \\
\hline \#311 & $62.5 \pm 1.2$ & $63.4 \pm 2.2$ & $46.5 \pm 5.3$ & $31.2 \pm 0.3$ & $27.7 \pm 0.1$ & $29.8 \pm 0.1$ \\
\hline \#552 & $60.1 \pm 1.8$ & $55.7 \pm 2.5$ & $47.3 \pm 2.6$ & $33.0 \pm 0.6$ & $29.1 \pm 0.2$ & $31.7 \pm 0.2$ \\
\hline \multirow[t]{2}{*}{ \#573 } & $61.7 \pm 1.2$ & $56.4 \pm 2.4$ & $41.8 \pm 2.7$ & $30.3 \pm 0.1$ & $28.6 \pm 0.2$ & $30.8 \pm 0.2$ \\
\hline & 8.0 & 9.0 & 10.0 & 11.0 & 12.0 & 13.0 \\
\hline \#191 & $30.8 \pm 0.3$ & $31.0 \pm 0.3$ & $31.2 \pm 0.2$ & $31.3 \pm 0.2$ & $32.6 \pm 0.1$ & $35.2 \pm 0.3$ \\
\hline \#309 & $29.9 \pm 0.1$ & $30.1 \pm 0.1$ & $30.1 \pm 0.2$ & $30.2 \pm 0.1$ & $33.0 \pm 0.1$ & $34.8 \pm 0.1$ \\
\hline \#311 & $29.9 \pm 0.1$ & $30.4 \pm 0.1$ & $30.4 \pm 0.2$ & $30.4 \pm 0.1$ & $33.5 \pm 0.1$ & $34.4 \pm 0.1$ \\
\hline \#552 & $31.3 \pm 0.3$ & $31.8 \pm 0.2$ & $32.0 \pm 0.1$ & $32.2 \pm 0.2$ & $34.2 \pm 0.2$ & $34.9 \pm 0.2$ \\
\hline \#573 & $30.9 \pm 0.1$ & $31.0 \pm 0.2$ & $31.2 \pm 0.1$ & $31.3 \pm 0.2$ & $34.1 \pm 0.4$ & $35.0 \pm 0.4$ \\
\hline
\end{tabular}

Pornsunthorntawee et al., 2008; Vaz et al., 2012). In sand-pack column assays performed with different Bacillus strains, Suthar and co-workers (2008) observed that the combination of surface and emulsifying activity resulted in higher oil recovery when compared with strains possessing merely surface activity, since emulsifiers stabilize oil-water emulsions, which facilitates oil displacement (Suthar et al., 2008).

\subsection{Effect of temperature, $\mathrm{pH}$ and salinity on biosurfactant stability}

In order to assess the effect of salinity on biosurfactant activity, culture broth supernatants were supplemented with different $\mathrm{NaCl}$ concentrations, ranging from 10 to $200 \mathrm{~g} / \mathrm{l}$, and surface tension was measured. Data obtained are presented in Table 5. The maximum surface tension reduction was reached with a $\mathrm{NaCl}$ concentration of $50 \mathrm{~g} / \mathrm{l}$ for all the isolates, and at $100 \mathrm{~g} / \mathrm{l}$ the surface tension values were still lower than the obtained at $10 \mathrm{~g} / \mathrm{l}$, similar to the results described by other authors (Yakimov et al., 1995; Nitschke and Pastore, 2006; Abdel-Mawgoud et al., 2008; Dastgheib et al., 2008; Ghojavand et al., 2008b). $\mathrm{NaCl}$ concentrations above $100 \mathrm{~g} / \mathrm{l}$ resulted in higher surface tension values.

The $\mathrm{pH}$ of biosurfactant-containing culture media was changed from 2.0 to 13.0 and surface tension values were measured (Table 6). Biosurfactant activity was retained at a $\mathrm{pH}$ range of 5.0-11.0 with a minimum deviation in surface tension for all the isolates, showing higher stability at alkaline than acidic conditions, and the minimum surface tension values were obtained at $\mathrm{pH} 6.0$ for all the isolates, as previously described (Nitschke and Pastore, 2006; Abdel-Mawgoud et al., 2008; Ghojavand et al., 2008b; Vaz et al., 2012). Below pH 5.0, surface tension increased due to the biosurfactant precipitation.

\section{Table 7}

Surface tension values $(\mathrm{mN} / \mathrm{m})$ and emulsification indexes $\left(E_{24}, \%\right)$ obtained with culture broth supernatants from the different isolates before and after exposure to $121^{\circ} \mathrm{C}$ for $20 \mathrm{~min}$. Surface tension values were determined six times at room temperature $\left(20^{\circ} \mathrm{C}\right)$. Emulsification indexes were calculated three times at $25{ }^{\circ} \mathrm{C}$. Results are expressed as means \pm standard deviations of values from triplicate experiments.

\begin{tabular}{llllll}
\hline & Before & & & After \\
\cline { 2 - 3 } \cline { 5 - 6 } & ST $(\mathrm{mN} / \mathrm{m})$ & $E_{24}(\%)$ & & ST $(\mathrm{mN} / \mathrm{m})$ & $E_{24}(\%)$ \\
\hline$\# 191$ & $31.8 \pm 0.1$ & $50.8 \pm 0.0$ & & $32.6 \pm 0.1$ & $42.4 \pm 0.0$ \\
$\# 309$ & $29.9 \pm 0.1$ & $50.8 \pm 0.0$ & & $30.0 \pm 0.1$ & $53.7 \pm 0.0$ \\
$\# 311$ & $29.8 \pm 0.0$ & $50.8 \pm 0.0$ & & $30.1 \pm 0.1$ & $53.7 \pm 0.0$ \\
$\# 552$ & $31.9 \pm 0.2$ & $46.6 \pm 1.9$ & & $32.8 \pm 0.2$ & $43.8 \pm 2.0$ \\
$\# 573$ & $30.6 \pm 0.3$ & $52.3 \pm 1.9$ & & $31.1 \pm 0.1$ & $52.3 \pm 1.9$ \\
\hline
\end{tabular}

Usually, lipopeptide biosurfactants retain their surface-active properties after incubation at $100{ }^{\circ} \mathrm{C}$ for $2 \mathrm{~h}$ (Ghojavand et al., 2008b), and their stability when exposed to $121^{\circ} \mathrm{C}$ has been described by several authors (Nitschke and Pastore, 2006; Abdel-Mawgoud et al., 2008; Dastgheib et al., 2008; Vaz et al., 2012). To study the stability of biosurfactants at high temperatures, culture broth supernatants obtained at the end of the fermentation were incubated at $121^{\circ} \mathrm{C}$ for $20 \mathrm{~min}$. Surface tension and emulsification activity were measured before and after heating. As can be seen from Table 7, the temperature increased had no negative effect in surface activity.

\section{Conclusion}

In the current study, $B$. subtilis strains exhibiting desirable properties for application in MEOR were isolated from crude oil samples. Some isolates grew under anaerobic conditions in medium with $\mathrm{NaCl}$ concentrations up to $100 \mathrm{~g} / \mathrm{l}$ and temperatures up to $45-50{ }^{\circ} \mathrm{C}$ and were not inhibited by the presence of hydrocarbons. The biosurfactants produced by those isolates have some properties, including thermo- and salt-tolerance; ability to reduce the surface tension of water to $30 \mathrm{mN} / \mathrm{m}$; ability to emulsify hydrocarbons and critical micelle concentrations of $0.02-0.03 \mathrm{~g} / \mathrm{l}$. Some $B$. subtilis isolates were also capable of degrading the heavier $n$-alkanes in different paraffinic mixtures, both under aerobic or anaerobic conditions at $40^{\circ} \mathrm{C}$. And some isolates (\#191 and \#309) exhibited simultaneously the ability for biosurfactant production and hydrocarbon degradation, making them promising candidates for MEOR. Their usefulness for MEOR applications will be further evaluated using laboratory scale sand-pack columns in the future.

\section{Acknowledgments}

This work was supported by PARTEX OIL AND GAS. Jorge F. B. Pereira acknowledges the financial support from Fundação para a Ciência e a Tecnologia through doctoral research grant SFRH/BD/ $60228 / 2009$.

\section{References}

Abdel-Mawgoud, A.M., Aboulwafa, M.M., Hassouna, N.A.H., 2008. Characterization of surfactin produced by Bacillus subtilis isolate BS5. Applied Biochemistry and Biotechnology 150, 289-303.

Banat, I.M., 1995. Biosurfactants production and possible uses in microbial enhanced oil recovery and oil pollution remediation: a review. Bioresource Technology $51,1-12$.

Banat, I.M., Franzetti, A., Gandolfi, I., Bestetti, G., Martinotti, M.G., Fracchia, L., Smyth, T.J., Marchant, R., 2010. Microbial biosurfactants production, applications and future potential. Applied Microbiology and Biotechnology 87, 427-444.

Binazadeh, M., Karimi, I.A., Li, Z., 2009. Fast biodegradation of long chain $n$-alkanes and crude oil at high concentration with Rhodococcus sp. Moj-3449. Enzyme and Microbial Technology 45, 195-202.

Bordoloi, N.K., Konwar, B.K., 2008. Microbial surfactant-enhanced mineral oil recovery under laboratory conditions. Colloids and Surfaces B: Biointerfaces 63, 73-82.

Brown, L.R., 2010. Microbial enhanced oil recovery (MEOR). Current Opinion in Microbiology 13, 1-5.

Das, M., Das, S.K., Mukherjee, R.K., 1998. Surface active properties of the culture filtrates of a Micrococcus species grown on n-alkanes and sugars. Bioresource Technology 63, 231-235.

Das, K., Mukherjee, A.K., 2007. Crude petroleum-oil biodegradation efficiency of Bacillus subtilis and Pseudomonas aeruginosa strains isolated from petroleum-oil contaminated soil from North-East India. Bioresource Technology 98, 1339-1345.

Dastgheib, S.S.M., Amoozegar, M.A., Elahi, E., Asad, S., Banat, I.M., 2008. Bioemulsifier production by a halothermophilic Bacillus strain with potential applications in microbially enhanced oil recovery. Biotechnology Letters 30 , 263-270.

Etoumi, A., El Musrati, I., El Gammoudi, B., El Behlil, M., 2008. The reduction of wax precipitation in waxy crude oils by Pseudomonas species. Journal of Industrial Microbiology and Biotechnology 35, 1241-1245.

Ghojavand, H., Vahabzadeh, F., Mehranian, M., Radmehr, M., Shahraki, A.K., Zolfagharian, F., Emadi, M.A., Roayaei, E., 2008a. Isolation of thermotolerant, 
halotolerant, facultative biosurfactant-producing bacteria. Applied Microbiology and Biotechnology 80, 1073-1085.

Ghojavand, H., Vahabzadeh, F., Roayaei, E., Shahraki, A.K., 2008b. Production and properties of a biosurfactant obtained from a member of the Bacillus subtilis group (PTCC 1696). Journal of Colloid and Interface Science 324, 172-176.

Gudiña, E.J., Teixeira, J.A., Rodrigues, L.R., 2010. Isolation and functional characterization of a biosurfactant produced by Lactobacillus paracasei. Colloids and Surfaces B: Biointerfaces 76, 298-304.

Grishchenkov, V.G., Townsend, R.T., McDonald, T.J., Autenrieth, R.L., Bonner, J.S. Boronin, A.M., 2000. Degradation of petroleum hydrocarbons by facultative anerobic bacteria under aerobic and anaerobic conditions. Process Biochemistry $35,889-896$.

Hao, D.H., Lin, J.Q., Song, X., Lin, J.Q., Su, Y.J., Qu, Y.B., 2008. Isolation, identification, and performance studies of a novel paraffin-degrading bacterium of Gordonia amicalis LH3. Biotechnology and Bioprocess Engineering 13, 61-68.

Hasanuzzaman, M., Ueno, A., Ito, H., Ito, Y., Yamamoto, Y., Yumoto, I., Okuyama, H. 2007. Degradation of long-chain $n$-alkanes (C36 and C40) by Pseudomonas aeruginosa strain WatG. International Biodeterioration and Biodegradation 59 40-43.

Javaheri, M., Jenneman, G.E., McInerney, M.J., Knapp, R.M., 1985. Anaerobic production of a biosurfactant by Bacillus licheniformis JF-2. Applied and Environmental Microbiology 50, 698-700.

Jenneman, G.E., McInerney, M.J., Knapp, R.M., Clark, J.B., Feero, J.M., Revus, D.E., Menzie, D.E., 1983. A halotolerant, biosurfactant producing Bacillus species potentially useful for enhanced oil recovery. Developments in Industrial Microbiology 24, 485-492.

Jinfeng, L., Lijun, M., Bozhong, M., Rulin, L., Fangtian, N., Jiaxi, Z., 2005. The field pilot of microbial enhanced oil recovery in a high temperature petroleum reservoir. Journal of Petroleum Science and Engineering 48, 265-271.

Kato, T., Haruki, M., Imanaka, T., Morikawa, M., Kanaya, S., 2001. Isolation and characterization of long chain alkane degrading Bacillus themoleovorans from deep subterranean petroleum reservoirs. Journal of Bioscience and Bioengineering 91, 64-70.

Lazar, I., Petrisor, I.G., Yen, T.F., 2007. Microbial enhanced oil recovery (MEOR) Petroleum Science and Technology 25, 1353-1366.

Li, Q., Kang, C., Wang, H., Liu, C., Zhang, C., 2002. Application of microbial enhanced oil recovery technique to Daqing Oilfield. Biochemical Engineering Journal 11, 197-199.

Lotfabad, T.B., Shourian, M., Roostaazad, R., Najafabadi, A.R., Adelzadeh, M.R. Noghabi, K.A., 2009. An efficient biosurfactant-producing bacterium Pseudomonas aeruginosa MR01, isolated from oil excavation areas in south of Iran. Colloids and Surfaces B: Biointerfaces 69, 183-193.

Nitschke, M., Pastore, G.M., 2006. Production and properties of a surfactant obtained from Bacillus subtilis grown on cassava wastewater. Bioresource Technology $97,336-341$.
Pornsunthorntawee, O., Arttaweeporn, N., Paisanjit, S., Somboonthanate, P., Abe, M., Rujiravanit, R., Chavadej, S., 2008. Isolation and comparison of biosurfactants produced by Bacillus subtilis PT2 and Pseudomonas aeruginosa SP4 for microbial surfactant-enhanced oil recovery. Biochemical Engineering Journal 42, 172-179.

Sabirova, J.S., Ferrer, M., Regenhardt, D., Timmis, K.N., Golyshin, P.N., 2006. Proteomic insights into metabolic adaptations in Alcanivorax borkumensis induced by alkane utilization. Journal of Bacteriology 188, 3763-3773.

Sen, R., 2008. Biotechnology in petroleum recovery: the microbial EOR. Progress in Energy and Combustion Science 34, 714-724.

She, Y.H., Zhang, F., Xia, J.J., Kong, S.Q., Wang, Z.L., Shu, F.C., Hu, J.M., 2011. Investigation of biosurfactant-producing indigenous microorganisms that enhance residue oil recovery in an oil reservoir after polymer flooding. Applied Biochemistry and Biotechnology 163, 223-234.

Simpson, D.R., Natraj, N.R., McInerney, M.J., Duncan, K.E., 2011. Biosurfactantproducing Bacillus are present in produced brines from Oklahoma oil reservoirs with a wide range of salinities. Applied Microbiology and Biotechnology 91, 1083-1093.

Suthar, H., Hingurao, K., Desai, A., Nerurkar, A., 2008. Evaluation of bioemulsifier mediated Microbial Enhanced Oil Recovery using sand pack column. Journal of Microbiological Methods 75, 225-230.

Vaz, A.D., Gudiña, E.J., Alameda, E.J., Teixeira, J.A., Rodrigues, L.R., 2012. Performance of a biosurfactant produced by a Bacillus subtilis strain isolated from crude oil samples as compared to commercial chemical surfactants. Colloids and Surfaces B: Biointerfaces 89, 167-174

Wang, L., Tang, Y., Wang, S., Liu, R.L., Liu, M.Z., Zhang, Y., Liang, F.L., Feng, L., 2006. Isolation and characterization of a novel thermophilic Bacillus strain degrading long-chain $n$-alkanes. Extremophiles 10 347-356.

Wentzel, A., Ellingsen, T.E., Kotlar, H.K., Zotchev, S.B., Throne-Holst, M., 2007. Bacterial metabolism of long-chain $n$-alkanes. Applied Microbiology and Biotechnology 76, 1209-1221.

Yakimow, M.M., Amro, M.M., Bock, M., Boseker, K., Fredrickson, H.L., Kessel, D.G. Timmis, K.N., 1997. The potential of Bacillus licheniformis strains for in situ enhanced oil recovery. Journal of Petroleum Science and Engineering 18 147-160.

Yakimow, M.M., Timmis, K.N., Wray, V., Fredrickson, H.L., 1995. Characterization of a new lipopeptide surfactant produced by thermotolerant and halotolerant subsurface Bacillus licheniformis BAS50. Applied and Environmental Microbiology 61, 1706-1713.

Youssef, N., Simpson, D.R., Duncan, K.E., McInerney, M.J., Folmsbee, M., Fincher, T. Knapp, R.M., 2007. In situ biosurfactant production by Bacillus strains injected into a limestone petroleum reservoir. Applied and Environmental Microbiology $73,1239-1247$

Youssef, N., Elshahed, M.S., Mclnerney, M.J., 2009. Microbial processes in oil fields: culprits, problems, and opportunities. Advances in Applied Microbiology 66 141-251. 